\title{
Catheter ablation of atrial fibrillation: current status, techniques, outcomes, and challenges
}

\author{
Gerhard Hindricks ${ }^{1,2}$, Alireza Sepehri Shamloo ${ }^{1}$, Radosław Lenarczyk ${ }^{3}$, Zbigniew Kalarus ${ }^{4}$, \\ Arash Arya ${ }^{1}$, Simon Kircher $^{1}$, Angeliki Darma ${ }^{1}$, Nikolaos Dagres ${ }^{1}$ \\ 'Department of Electrophysiology, Heart Centre Leipzig at University of Leipzig, Leipzig, Germany \\ 2Leipzig Heart Institute, Leipzig, Germany \\ ${ }^{3} 1^{\text {st }}$ Department of Cardiology and Angiology, Silesian Centre for Heart Diseases, Zabrze, Poland \\ ${ }^{4}$ Department of Cardiology, Congenital Heart Disease and Electrotherapy, School of Medicine with Division of Densitry SMDZ in Zabrze, \\ Medical University of Silesia, Silesian Centre for Heart Diseases, Katowice, Poland
}

\begin{abstract}
A bstract
Atrial fibrillation (AF) is the most common human arrhythmia. Interventional treatment with catheter ablation is an established technique that is increasingly applied and has become one of the main treatment modalities in patients with AF. Ablation results in significant improvement of symptoms and the quality of life. There is as yet no clear evidence of any impact of the procedure on hard clinical endpoints, except in patients with heart failure, who seem to benefit significantly from ablation. The cornerstone of the procedure is the achievement of pulmonary vein isolation. Radiofrequency energy is the main applied energy source, but cryoballoon ablation has emerged as a safe and effective alternative to radiofrequency ablation. Additional ablation strategies and novel technical features have been proposed but without unequivocal proof of clinical benefit. The most promising of these seems to be substrate mapping of the left atrium with substrate modification in areas with low voltage as an adjunct to pulmonary vein isolation. Complication rates remain considerable despite accumulated experience and can be partly reduced by application of preventive measures.
\end{abstract}

Key words: atrial fibrillation, catheter ablation, complications

Kardiol Pol 2018; 76, 12: 1680-1686

\section{INTRODUCTION}

Atrial fibrillation (AF) is the most common human arrhythmia, causing significant morbidity and mortality, and its prevalence is expected to increase substantially due to the growing age of the population and the increase in the prevalence of risk factors predisposing to AF [1]. Interventional treatment with catheter ablation has emerged in the last two decades as a novel interventional technique for treatment of $\mathrm{AF}$, with success rates that are substantially better than those of medical treatment, with regard to successful maintenance of sinus rhythm. Therefore, it is not surprising that the number of AF ablations performed throughout Europe has increased significantly; the method has become one of the pillars in the management of patients with AF and is recommended in the guidelines of the European Society of Cardiology for several clinical settings [2-4]. Despite this great success, significant uncertainties regarding AF ablation remain, and important challenges still lie ahead.

\section{CHOICE OF THE APPROPRIATE TECHNIQUE FOR AF ABLATION AND ITS OUTCOME}

Following the seminal recognition of the importance of ectopic beats originating from the pulmonary veins $(\mathrm{PVS})$ for the initiation of AF [5], AF ablation techniques are mainly focused on electrical isolation of the PVs from the surrounding atrial myocardium. Indeed, achievement of complete electrical pulmonary vein isolation (PVI) is the cornerstone of successful AF ablation [6]. However, the choice of the appropriate ablation technique, in particular considering the underlying substrate of the individual patient, remains an issue.

Currently, the majority of AF ablation procedures are performed with the use of a radiofrequency (RF) energy source [6]. However, recent findings challenge the dominant role of RF ablation. In particular, cryoablation has emerged as a solid alternative that can be applied safely and with similar success rates compared with RF ablation, particularly in patients with paroxysmal AF, as recently demonstrated in the FIRE AND ICE

\section{Address for correspondence:}

Dr. Nikolaos Dagres, Department of Electrophysiology, Heart Centre Leipzig at University of Leipzig, Strümpellstr. 39, 04289 Leipzig, Germany, tel: +49 3418651410, e-mail: dagresnikolaos@gmail.com

Received: 5.11 .2018 
trial [7]. The efficacy and safety of cryoballoon ablation in paroxysmal AF, including more challenging or specific clinical settings such as elderly patients, patients with heart failure, or patients undergoing first-line ablation, have been confirmed in several other studies [8-10]. Cryoablation may have the additional advantage of shorter procedure times [11, 12] and appears to be less operator-dependent and more reproducible compared with RF ablation [13]. This is an important aspect because success rates of RF ablation for AF are reported to be operator-dependent [14]. Further studies have demonstrated that the satisfactory results of cryoballoon ablation are independent of PV anatomy, which means that the technique can be applied in the presence of different anatomical variants of PV with similar results [15]. Complication rates of cryoablation are comparable with those of RF ablation procedures but with a different complication spectrum, as will be described in the following sections. Overall, cryoablation has emerged as a solid alternative to RF ablation for the treatment of paroxysmal $\mathrm{AF}$ and is expected to gain further significance in the future [16].

A whole variety of other circular multi-electrode systems have been proposed with the aim of easy, practical, and reliable achievement of PVI [17-22]. Despite promising initial results, these devices have not managed to become an established tool for AF ablation, partly because severe complications have been reported after the use of one of them [23].

Overall, the success rate of catheter ablation for AF, defined as maintenance of sinus rhythm and freedom from AF recurrences without antiarrhythmic drugs, is $60 \%$ to $65 \%$ at one year [6]. In longer follow-up, this rate is reduced [24] and has been reported to be as low as $40 \%$ at five years after a single procedure [25]. Apart from the maintenance of sinus rhythm, the procedure has a significant effect on symptoms, quality of life and functional capacity that are substantially improved after ablation [26-28]. Reassuringly, no significant differences in the outcome of the procedure have been reported across different geographies [29].

In patients with persistent $\mathrm{AF}$, the outcome of $\mathrm{AF}$ ablation is poorer than in patients with paroxysmal AF [6], probably due to the underlying substrate, which is in many cases more complex and potentially reduces the success rates of techniques focusing solely on PVI. Thus, in a recent meta-analysis of studies on AF ablation in patients with persistent and long-standing persistent AF, efficacy of a single ablation procedure was reported to be as low as $43 \%$ [30]. To increase the success rates of ablation in these patients, several techniques have been proposed, such as targeting of complex fractionated electrograms, linear ablation in the left atrium, rotor mapping, and ablation or substrate modification [31]. However, the additive value of most of these strategies is either absent or not clear yet. In the STAR AF II trial, the placement of linear lesions and the ablation of complex fractionated electrograms did not result in better outcome compared with PVI alone in patients with persistent AF [32], and these results have been corroborated by subsequent publications [33, 34]. Rotor mapping and ablation is a safe technique [35], but evidence regarding the associated benefits is also contradictory [36, 37]. Substrate-based ablation with targeted ablation of low-voltage areas in the left atrium by placement of strategic lesions in addition to PVI seems to be promising, resulting in higher success rates compared with conventional strategies, as recently shown in a randomised comparison of these two approaches $[38,39]$. Examples of assessment of the left atrial substrate and of a substrate-based ablation are shown in Figures 1 and 2 .

Interestingly, cryoballoon ablation may also play a significant role in persistent $\mathrm{AF}$, with several studies reporting favourable outcome and similar success rates to RF ablation [40-42]. Additional ablation lesions such as roof lesions or empirical left atrial appendage isolation that can be placed with the cryoballoon during the ablation procedure have been proposed in order to increase the success rate [43, 44]. However, the need for and the additive value of such techniques remain to be confirmed in larger studies, and persistent AF is reported as a significant factor associated with recurrences in the context of cryoablation [45].

Adenosine administration for demonstration of non-PV triggers and for unmasking dormant PV conduction has been proposed as a strategy to increase the success rate of the procedure [46]. This was confirmed in a recent meta-analysis indicating a potential benefit of adenosine administration for detection of dormant conduction [47]. Nevertheless, adenosine testing cannot be used as a substitute for the waiting period following successful PVI [48] but rather as an adjunct.

Technical developments constantly provide additional options for safe and successful performance of the procedure. The advent of three-dimensional mapping systems has completely transformed the clinical routine of electrophysiology. Particularly in the field of $\mathrm{AF}$, these mapping systems have made the wide application of AF ablation possible [49]. Subsequent technical features such as measurement of the ablation catheter contact force and calculation of the force-time integral have recently been proposed as additional tools for the achievement of durable PVI [50-54]. Although some reports indicate a reduction of fluoroscopy time and radiation dose with the use of these features, their additive value [55], and in particular the additive benefit compared with conventional ablation techniques, still needs to be determined. Nevertheless, the complication rate does not seem to be positively affected [55]. High-density mapping of the left atrium has also recently been introduced [56-58] and has been reported to improve results of the procedure. The additive value of this novel mapping technology remains to be confirmed in larger studies.

\section{SAFETY OF AF ABLATION}

Given the elective character of the procedure, procedural safety as reflected by the associated complications is of para- 


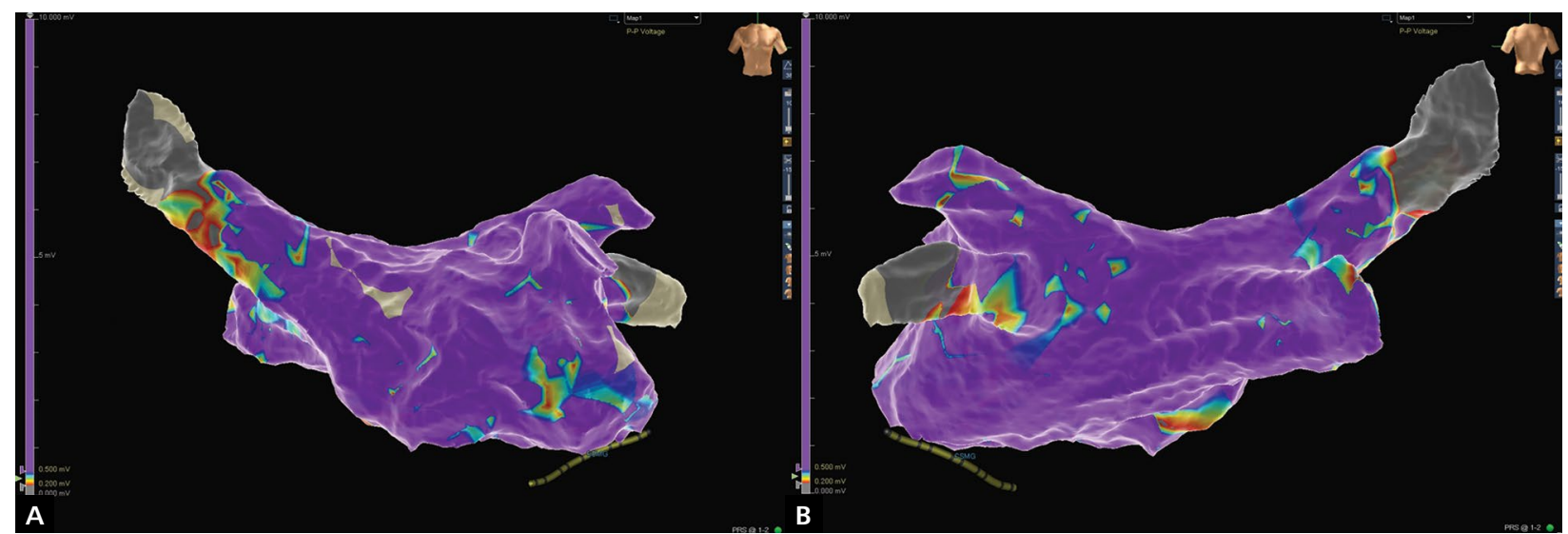

Figure 1. Voltage mapping of the left atrium during an ablation procedure for atrial fibrillation. Depicted are anteroposterior (A) and posteroanterior (B) views of the three-dimensional reconstruction of the left atrium. The purple colour indicates normal voltage in the left atrium with a threshold of $0.5 \mathrm{mV}$

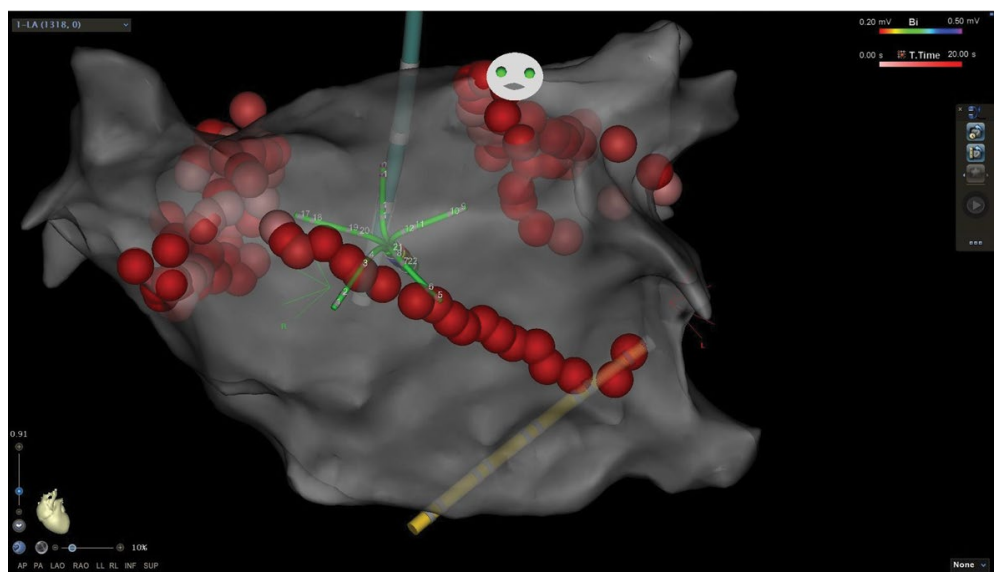

Figure 2. Substrate modification in an atrial fibrillation ablation procedure. Depicted is the three-dimensional reconstruction of the left atrium. The red dots show the ablation lesions. Circumferential ablation lesions are placed around the left and the right pulmonary veins. Additionally, a linear lesion is placed across the septum due to abnormal voltage in this area

mount importance. Complication rates of AF ablation seem to be influenced by patient characteristics. With a growing number of comorbidities, the complication risk increases [59-61]. Although temporal trends show a decrease in the complication rates over the last 15 years [59], they remain considerable, even in high-volume centres [62]. The most frequent, immediately threatening complication is cardiac tamponade, which occurs in approximately $0.9 \%$ to $1.3 \%$ of cases $[6,63]$. The majority of cases with tamponade can be successfully managed with pericardiocentesis, but in a small minority, emergent surgical treatment may become necessary [64].

The second most important complication in terms of severity and risk of permanent sequelae consists of thromboembolic events that may lead to stroke or transient ischaemic attacks in approximately $0.4 \%$ of cases $[6,65]$. These are observed predominantly directly after the procedure or within the first $24 \mathrm{~h}$, and fortunately in most cases they have a relatively benign course [65].

A rare but very important complication, because of the life-threatening character and the poor outcome, is atrial-oesophageal fistula caused by thermal injury of the oesophagus due to the anatomic vicinity of the oesophagus to the posterior left atrial wall. This complication occurs with a time delay of one to four weeks after the procedure in approximately $1 \%$ of the cases [66], although earlier manifestations are possible [6]. Several techniques are applied to prevent the development of this catastrophic complication [67]. The preventive action that is most frequently applied in clinical practice is measurement of the intraluminal oesophageal temperature [68]. In the event of temperature rise, energy application is terminated in order to prevent oesophageal injury. The findings regarding the impact of these preventive measures on 
the outcome of the procedure are contradictory. Although some studies report that preventive premature termination of RF energy during PVI does not affect adversely the long-term outcome of the procedure $[69,70]$, other studies report an association of segments with PV reconnections in patients undergoing redo procedures and elevated oesophageal temperature during the index procedure [71]. It is important to know that the risk of atrial-oesophageal fistula still exists and that the above-mentioned preventive actions have limitations because the measured temperature does not necessarily reflect the true maximal temperature of the oesophagus [72], and more importantly, several cases have been reported to occur despite oesophageal temperature monitoring [66].

Cryoballoon ablation shows some differences from RF ablation with regard to complications. In particular, phrenic nerve palsy, caused by the vicinity of the phrenic nerve to the ablation field, is a major complication after cryoballoon ablation [41, 73-75]. Different measures for prevention of this complication are applied in clinical practice [76]. Among them, the most easily applied is palpation of diaphragmatic contraction at the time of pacing of the phrenic nerve during the procedure.

\section{CRITICAL APPRAISAL OF THE PROCEDURE}

Despite all successes of AF ablation in terms of effective maintenance of sinus rhythm and symptom relief, a major determinant of the value of the procedure in the overall context of management of AF patients will be the direct comparison with conservative treatment in terms of important clinical outcomes, such as mortality and hospitalisations. The publication of the results of the CABANA trial, the only large randomised comparison between catheter ablation and drug treatment with hard clinical endpoints, will be crucial for this assessment. Presentation of the main results of the trial showed no significant difference between ablation and drug treatment in the composite clinical primary endpoint in the intention-to-treat analysis [77]. The full results, once available, will provide further insight into the lessons that need to be learned from this very important trial.

A specific patient population that may derive significant benefit from the procedure in terms of hard clinical endpoints is the group of patients with heart failure. Previous studies have demonstrated a significant improvement of left ventricular function following catheter ablation for $\mathrm{AF}$ in patients with reduced left ventricular systolic function [78-80]. Recently, the CASTLE-AF trial showed a marked reduction of the primary endpoint that was a composite of death from any cause or hospitalisation for worsening heart failure in patients with $\mathrm{AF}$ and a reduced left ventricular ejection fraction of $\leq 35 \%$ [81] randomised to catheter ablation, compared with conservative treatment. Recurrences of the arrhythmia after the procedure seem to strongly predict major adverse outcomes during follow-up [82].

\section{CONCLUSIONS}

Atrial fibrillation ablation has developed into a main treatment modality for patients with $\mathrm{AF}$, resulting in significant improvement of symptoms and the quality of life. Until now, there has been no evidence of any impact of the procedure on hard clinical endpoints, except in patients with heart failure. PVI is the cornerstone of the procedure, most widely achieved by RF ablation, whereas cryoballoon ablation has emerged as a safe and effective alternative to RF. Additional ablation strategies have been proposed, especially for persistent $A F$, but an unequivocal positive impact on the success rate of these procedures compared with $\mathrm{PVI}$ only remains to be demonstrated. Similarly, there are a variety of novel technical developments, but their additive value remains to be proven. Complication rates remain considerable even in high-volume centres, despite accumulated experience; preventive measures during the procedure may reduce the occurrence of some threatening adverse events.

Conflict of interest: Gerhard Hindricks and Nikolaos Dagres report research grants from Abbott, Biotronik, Boston Scientific, and Medtronic to the institution without personal financial benefits. Other authors declare no conflict of interest.

\section{References}

1. Kirchhof P, Breithardt G, Bax J, et al. A roadmap to improve the quality of atrial fibrillation management: proceedings from the fifth Atrial Fibrillation Network/European Heart Rhythm Association consensus conference. Europace. 2016; 18(1): 37-50, doi: 10.1093/europace/euv304, indexed in Pubmed: 26481149.

2. Raatikainen MJ, Arnar DO, Merkely B, et al. A Decade of Information on the Use of Cardiac Implantable Electronic Devices and Interventional Electrophysiological Procedures in the European Society of Cardiology Countries: 2017 Report from the European Heart Rhythm Association. Europace. 2017; 19(suppl_2): ii1-ii90, doi: 10.1093/europace/eux258, indexed in Pubmed: 28903470.

3. Lenarczyk R, Mitręga K, Mazurek M, et al. Polish and European management strategies in patients with atrial fibrillation. Data from the EURObservational Research Programme-Atrial Fibrillation General Registry Pilot Phase (EORP-AF Pilot). Pol Arch Med Wewn. 2016; 126(3): 138-148, doi: 10.20452/pamw.3322, indexed in Pubmed: 27000745.

4. Kirchhof P, Benussi S, Kotecha D, et al. 2016 ESC Guidelines for the management of atrial fibrillation developed in collaboration with EACTS. Europace. 2016; 18(11): 1609-1678, doi: 10.1093/europace/euw295.

5. Haïssaguerre M, Jaïs P, Shah DC, et al. Spontaneous initiation of atrial fibrillation by ectopic beats originating in the pulmonary veins. N Engl J Med. 1998; 339(10): 659-666, doi: 10.1056/NEJM199809033391003, indexed in Pubmed: 9725923.

6. Arbelo E, Brugada J, Blomström-Lundqvist C, et al. Contemporary management of patients undergoing atrial fibrillation ablation: in-hospital and 1-year follow-up findings from the ESC-EHRA atrial fibrillation ablation long-term registry. Eur Heart J. 2017; 38(17): 1303-1316, doi: 10.1093/eurheartj/ehw564, indexed in Pubmed: 28104790.

7. Kuck KH, Brugada J, Fürnkranz A, et al. Cryoballoon or Radiofrequency Ablation for Paroxysmal Atrial Fibrillation. N Engl J Med. 2016; 374(23): 2235-2245, doi: 10.1056/NEJMoa1602014, indexed in Pubmed: 27042964. 
8. Abugattas JP, Iacopino S, Moran D, et al. Efficacy and safety of the second generation cryoballoon ablation for the treatment of paroxysmal atrial fibrillation in patients over 75 years: a comparison with a younger cohort. Europace. 2017; 19(11): 1798-1803, doi: 10.1093/europace/eux023, indexed in Pubmed: 28402529.

9. Pruszkowska P, Lenarczyk R, Gumprecht J, et al. Cryoballoon ablation of atrial fibrillation in patients with advanced systolic heart failure and cardiac implantable electronic devices. Kardiol Pol. 2018; 76(7): 1081-1088, doi: 10.5603/KP.a2018.0068, indexed in Pubmed: 29528482.

10. Straube F, Dorwarth U, Ammar-Busch S, et al. First-line catheter ablation of paroxysmal atrial fibrillation: outcome of radiofrequency vs. cryoballoon pulmonary vein isolation. Europace. 2016; 18(3): 368-375, doi: 10.1093/europace/euv271, indexed in Pubmed: 26504108.

11. Chen YH, Lu ZY, Xiang Y, et al. Cryoablation vs. radiofrequency ablation for treatment of paroxysmal atrial fibrillation: a systematic review and meta-analysis. Europace. 2017; 19(5): 784-794, doi: 10.1093/europace/euw330, indexed in Pubmed: 28065886.

12. Buiatti A, von Olshausen G, Barthel P, et al. Cryoballoon vs. radiofrequency ablation for paroxysmal atrial fibrillation: an updated meta-analysis of randomized and observational studies. Europace. 2017; 19(3): 378-384, doi: 10.1093/europace/euw262, indexed in Pubmed: 27702864.

13. Providencia R, Defaye P, Lambiase PD, et al. Results from a multicentre comparison of cryoballoon vs. radiofrequency ablation for paroxysmal atrial fibrillation: is cryoablation more reproducible? Europace. 2017; 19(1): 48-57, doi: 10.1093/europace/euw080, indexed in Pubmed: 27267554.

14. Sairaku A, Yoshida Y, Nakano Y, et al. Who is the operator, that is the question: a multicentre study of catheter ablation of atrial fibrillation. Europace. 2016; 18(9): 1352-1356, doi: 10.1093/europace/euv424, indexed in Pubmed: 26838689.

15. Khoueiry Z, Albenque JP, Providencia R, et al. Outcomes after cryoablation vs. radiofrequency in patients with paroxysmal atrial fibrillation: impact of pulmonary veins anatomy. Europace. 2016; 18(9): 1343-1351, doi: 10.1093/europace/euv419, indexed in Pubmed: 26817755.

16. Chen J, Lenarczyk R, Boveda S, et al. Scientific Initiative Committee, European Heart Rhythm Association. Cryoablation for treatment of cardiac arrhythmias: results of the European Heart Rhythm Association survey. Europace. 2017; 19(2): 303-307, doi: 10.1093/europace/eux001, indexed in Pubmed: 28165525.

17. Wakili R, Siebermair J, Fichtner S, et al. One-year clinical outcome after ablation with a novel multipolar irrigated ablation catheter for treatment of atrial fibrillation: potential implications for clinical use. Europace. 2016; 18(8): 1170-1178, doi: 10.1093/europace/euv349, indexed in Pubmed: 26759125.

18. Laish-Farkash A, Khalameizer V, Fishman E, et al. Safety, efficacy, and clinical applicability of pulmonary vein isolation with circular multi-electrode ablation systems: PVAC ${ }^{\circledR}$ vs. $\mathrm{nMARQ}^{\mathrm{TM}}$ for atrial fibrillation ablation. Europace. 2016; 18(6): 807-814, doi: 10.1093/europace/euv258, indexed in Pubmed: 26589623.

19. Leitz P, Güner F, Wasmer K, et al. Data on procedural handling and complications of pulmonary vein isolation using the pulmonary vein ablation catheter GOLD®. Europace. 2016; 18(5): 696-701, doi: 10.1093/europace/euv355, indexed in Pubmed: 26705559.

20. Wasmer K, Foraita P, Leitz P, et al. Safety profile of multielectrode-phased radiofrequency pulmonary vein ablation catheter and irrigated radiofrequency catheter. Europace. 2016; 18(1): 78-84, doi: 10.1093/europace/euv046, indexed in Pubmed: 25883082.

21. Pavlović N, Sticherling C, Knecht S, et al. One-year follow-up after irrigated multi-electrode radiofrequency ablation of persistent atrial fibrillation. Europace. 2016; 18(1): 85-91, doi: 10.1093/europace/euv020, indexed in Pubmed: 25883078.
22. Rosso R, Halkin A, Michowitz Y, et al. Radiofrequency ablation of paroxysmal atrial fibrillation with the new irrigated multipolar nMARQ ablation catheter: verification of intracardiac signals with a second circular mapping catheter. Heart Rhythm. 2014; 11(4): 559-565, doi: 10.1016/j.hrthm.2013.12.029, indexed in Pubmed: 24384521.

23. Vurma M, Dang L, Brunner-La Rocca HP, et al. Safety and efficacy of the nMARQ catheter for paroxysmal and persistent atrial fibrillation. Europace. 2016; 18(8): 1164-1169, doi: 10.1093/europace/euw048, indexed in Pubmed: 27247003.

24. Steinberg JS, Palekar R, Sichrovsky T, et al. Very long-term outcome after initially successful catheter ablation of atrial fibrillation. Heart Rhythm. 2014; 11(5): 771-776, doi: 10.1016/j. hrthm.2014.02.003, indexed in Pubmed: 24508206.

25. Teunissen C, Kassenberg W, van der Heijden JF, et al. Five-year efficacy of pulmonary vein antrum isolation as a primary ablation strategy for atrial fibrillation: a single-centre cohort study. Europace. 2016; 18(9): 1335-1342, doi: 10.1093/europace/euv439, indexed in Pubmed: 26838694.

26. Woźniak-Skowerska IM, Skowerski MJ, Hoffmann A, et al. Quality of life in patients with paroxysmal atrial fibrillation after circumferential pulmonary vein ablation. Kardiol Pol. 2016; 74(3): 244-250, doi: 10.5603/KP.a2015.0160, indexed in Pubmed: 26305366.

27. Cosedis Nielsen J, Johannessen A, Raatikainen P, et al. Radiofrequency ablation as initial therapy in paroxysmal atrial fibrillation. N Engl J Med. 2012; 367(17): 1587-1595, doi: 10.1056/NEJMoa1113566, indexed in Pubmed: 23094720.

28. Fiala M, Bulková V, Škňouřil L, et al. Functional improvement after successful catheter ablation for long-standing persistent atrial fibrillation. Europace. 2016; 19(11): 1781-1789, doi: 10.1093/europace/euw282.

29. Riahi S, Arbelo E, Brugada J, et al. Regional differences in referral, procedures, and outcome after ablation for atrial fibrillation in Europe: a report from the Atrial Fibrillation Ablation Pilot Registry of the European Society of Cardiology. Europace. 2016; 18(2): 191-200, doi: 10.1093/europace/euv386, indexed in Pubmed: 26647447.

30. Clarnette JA, Brooks AG, Mahajan R, et al. Outcomes of persistent and long-standing persistent atrial fibrillation ablation: a systematic review and meta-analysis. Europace. 2017 [Epub ahead of print], doi: 10.1093/europace/eux297, indexed in Pubmed: 29267853.

31. Wynn GJ, Das M, Bonnett LJ, et al. Efficacy of catheter ablation for persistent atrial fibrillation: a systematic review and meta-analysis of evidence from randomized and nonrandomized controlled trials. Circ Arrhythm Electrophysiol. 2014; 7(5): 841-852, doi: 10.1161/CIRCEP.114.001759, indexed in Pubmed: 25132078.

32. Verma A, Jiang Cy, Betts TR, et al. Approaches to catheter ablation for persistent atrial fibrillation. N Engl J Med. 2015; 372(19): 1812-1822, doi: 10.1056/NEJMoa1408288, indexed in Pubmed: 25946280

33. Scott PA, Silberbauer J, Murgatroyd FD. The impact of adjunctive complex fractionated atrial electrogram ablation and linear lesions on outcomes in persistent atrial fibrillation: a meta-analysis. Europace. 2016; 18(3): 359-367, doi: 10.1093/europace/euv351, indexed in Pubmed: 26559915.

34. Providência R, Lambiase P, Srinivasan N, et al. Is there still a role for complex fractionated atrial electrogram ablation in addition to pulmonary vein isolation in patients with paroxysmal and persistent atrial fibrillation? Circ Arrhythmia Electrophysiol. 2015; 8(5): 1017-1029, doi: 10.1161/circep.115.003019.

35. Krummen DE, Baykaner T, Schricker AA, et al. Multicentre safety of adding Focal Impulse and Rotor Modulation (FIRM) to conventional ablation for atrial fibrillation. Europace. 2017; 19(5): 769-774, doi: 10.1093/europace/euw377, indexed in Pubmed: 28339546. 
36. Hindricks G, Dagres N. New Strategies to Improve Rhythm Outcome of Catheter Ablation of Persistent and Longstanding Persistent Atrial Fibrillation: Hunting Rotors and Focal Sources. JACC Clin Electrophysiol. 2016; 2(6): 679-681, doi: 10.1016/j. jacep.2016.10.003, indexed in Pubmed: 29759745.

37. Gianni C, Mohanty S, Di Biase L, et al. Acute and early outcomes of focal impulse and rotor modulation (FIRM)-guided rotors-only ablation in patients with nonparoxysmal atrial fibrillation. Heart Rhythm. 2016; 13(4): 830-835, doi: 10.1016/j.hrthm.2015.12.028, indexed in Pubmed: 26706193.

38. Kircher S, Arya A, Altmann D, et al. Individually tailored vs. standardized substrate modification during radiofrequency catheter ablation for atrial fibrillation: a randomized study. Europace. 2018; 20(11): 1766-1775, doi: 10.1093/europace/eux310, indexed in Pubmed: 29177475.

39. Rolf S, Kircher S, Arya A, et al. Tailored atrial substrate modification based on low-voltage areas in catheter ablation of atrial fibrillation. Circ Arrhythm Electrophysiol. 2014; 7(5): 825-833, doi: 10.1161/CIRCEP.113.001251, indexed in Pubmed: 25151631.

40. Shao M, Shang L, Shi J, et al. The safety and efficacy of second-generation cryoballoon ablation plus catheter ablation for persistent atrial fibrillation: A systematic review and meta-analysis. PLoS One. 2018; 13(10): e0206362, doi: 10.1371/journal. pone.0206362, indexed in Pubmed: 30359452.

41. Ciconte G, Ottaviano L, de Asmundis C, et al. Pulmonary vein isolation as index procedure for persistent atrial fibrillation: One-year clinical outcome after ablation using the second-generation cryoballoon. Heart Rhythm. 2015; 12(1): 60-66, doi: 10.1016/j. hrthm.2014.09.063, indexed in Pubmed: 25281891.

42. Koektuerk B, Yorgun H, Hengeoez O, et al. Cryoballoon ablation for pulmonary vein isolation in patients with persistent atrial fibrillation. Circ Arrhythmia Electrophysiol. 2015; 8(5): 1073-1079, doi: 10.1161/circep.115.002776.

43. Kuniss M, Greiß H, Pajitnev D, et al. Cryoballoon ablation of persistent atrial fibrillation: feasibility and safety of left atrial roof ablation with generation of conduction block in addition to antral pulmonary vein isolation. Europace. 2017; 19(7): 1109-1115, doi: 10.1093/europace/euw146, indexed in Pubmed: 27738068.

44. Yorgun H, Canpolat U, Kocyigit D, et al. Left atrial appendage isolation in addition to pulmonary vein isolation in persistent atrial fibrillation: one-year clinical outcome after cryoballoon-based ablation. Europace. 2017; 19(5): 758-768, doi: 10.1093/europace/eux005, indexed in Pubmed: 28340073.

45. Irfan G, de Asmundis C, Mugnai G, et al. One-year follow-up after second-generation cryoballoon ablation for atrial fibrillation in a large cohort of patients: a single-centre experience. Europace. 2016; 18(7): 987-993, doi: 10.1093/europace/euv365, indexed in Pubmed: 26705562.

46. Macle L, Khairy P, Weerasooriya R, et al. Adenosine-guided pulmonary vein isolation for the treatment of paroxysmal atrial fibrillation: an international, multicentre, randomised superiority trial. Lancet. 2015; 386(9994): 672-679, doi: 10.1016/S01406736(15)60026-5, indexed in Pubmed: 26211828.

47. Chen YH, Lin H, Xie CL, et al. Role of adenosine-guided pulmonary vein isolation in patients undergoing catheter ablation for atrial fibrillation: a meta-analysis. Europace. 2017; 19(4): 552-559, doi: 10.1093/europace/euw201, indexed in Pubmed: 28431050.

48. Teunissen C, Clappers N, Kassenberg W, et al. Time matters: adenosine testing immediately after pulmonary vein isolation does not substitute a waiting period. Europace. 2017 19(7): 1140-1145, doi: 10.1093/europace/euw173, indexed in Pubmed: 27702849.

49. Eitel C, Hindricks G, Dagres N, et al. EnSite Velocity cardiac mapping system: a new platform for 3D mapping of cardiac arrhythmias. Expert Rev Med Devices. 2010; 7(2): 185-192, doi: 10.1586/erd.10.1, indexed in Pubmed: 20214424.
50. Das M, Loveday JJ, Wynn GJ, et al. Ablation index, a novel marker of ablation lesion quality: prediction of pulmonary vein reconnection at repeat electrophysiology study and regional differences in target values. Europace. 2017; 19(5): 775-783, doi: 10.1093/europace/euw105, indexed in Pubmed: 27247002.

51. Itoh T, Kimura M, Tomita H, et al. Reduced residual conduction gaps and favourable outcome in contact force-guided circumferential pulmonary vein isolation. Europace. 2016; 18(4): 531-537, doi: 10.1093/europace/euv206, indexed in Pubmed: 26346921.

52. Chinitz LA, Melby DP, Marchlinski FE, et al. Safety and efficiency of porous-tip contact-force catheter for drug-refractory symptomatic paroxysmal atrial fibrillation ablation: results from the SMART SF trial. Europace. 2017 [Epub ahead of print], doi: 10.1093/europace/eux264, indexed in Pubmed: 29016769.

53. Afzal MR, Chatta J, Samanta A, et al. Use of contact force sensing technology during radiofrequency ablation reduces recurrence of atrial fibrillation: A systematic review and meta-analysis. Heart Rhythm. 2015; 12(9): 1990-1996, doi: 10.1016/j. hrthm.2015.06.026, indexed in Pubmed: 26091856.

54. Makimoto $\mathrm{H}$, Lin $\mathrm{T}$, Rillig $\mathrm{A}$, et al. In vivo contact force analysis and correlation with tissue impedance during left atrial mapping and catheter ablation of atrial fibrillation. Circ Arrhythm Electrophysiol. 2014; 7(1): 46-54, doi: 10.1161/CIRCEP.113.000556, indexed in Pubmed: 24363353.

55. Lee G, Hunter RJ, Lovell MJ, et al. Use of a contact force-sensing ablation catheter with advanced catheter location significantly reduces fluoroscopy time and radiation dose in catheter ablation of atrial fibrillation. Europace. 2016; 18(2): 211-218, doi: 10.1093/europace/euv186, indexed in Pubmed: 26318548.

56. Wójcik M, Konarski Ł, Błaszczyk R, et al. High-density bipolar voltage mapping for substrate-guided ablation of atrial fibrillation. Kardiol Pol. 2018; 76(7): 1115, doi: 10.5603/KP.2018.0138, indexed in Pubmed: 29984814.

57. Segerson NM, Lynch B, Mozes J, et al. High-density mapping and ablation of concealed low-voltage activity within pulmonary vein antra results in improved freedom from atrial fibrillation compared to pulmonary vein isolation alone. Heart Rhythm. 2018; 15(8): 1158-1164, doi: 10.1016/j.hrthm.2018.04.035, indexed in Pubmed: 29729399.

58. García-Bolao I, Ballesteros G, Ramos P, et al. Identification of pulmonary vein reconnection gaps with high-density mapping in redo atrial fibrillation ablation procedures. Europace. 2017 [Epub ahead of print], doi: 10.1093/europace/eux184, indexed in Pubmed: 28637187.

59. Yang E, Ipek EG, Balouch M, et al. Factors impacting complication rates for catheter ablation of atrial fibrillation from 2003 to 2015. Europace. 2017; 19(2): 241-249, doi: 10.1093/europace/euw178, indexed in Pubmed: 28172794.

60. De Greef Y, Ströker E, Schwagten B, et al. Complications of pulmonary vein isolation in atrial fibrillation: predictors and comparison between four different ablation techniques: Results from the MIddelheim PVI-registry. Europace. 2017 [Epub ahead of print], doi: 10.1093/europace/eux233, indexed in Pubmed: 29016870.

61. Inoue K, Murakawa Y, Nogami A, et al. Clinical and procedural predictors of early complications of ablation for atrial fibrillation: analysis of the national registry data. Heart Rhythm. 2014; 11(12): 2247-2253, doi: 10.1016/j.hrthm.2014.08.021, indexed in Pubmed: 25131666.

62. Dagres N, Hindricks G, Kottkamp H, et al. Complications of atrial fibrillation ablation in a high-volume center in 1,000 procedures: still cause for concern? J Cardiovasc Electrophysiol. 2009; 20(9): 1014-1019, doi: 10.1111/j.1540-8167.2009.01493.x, indexed in Pubmed: 19490383.

63. Michowitz Y, Rahkovich M, Oral H, et al. Effects of sex on the incidence of cardiac tamponade after catheter ablation of atrial fibrillation: results from a worldwide survey in 34943 atrial fibrillation ablation procedures. Circ Arrhythm Electrophysiol. 
2014; 7(2): 274-280, doi: 10.1161/CIRCEP.113.000760, indexed in Pubmed: 24519888.

64. Hamaya R, Miyazaki S, Taniguchi H, et al. Management of cardiac tamponade in catheter ablation of atrial fibrillation: single-centre 15 year experience on 5222 procedures. Europace. 2018; 20(11): 1776-1782, doi: 10.1093/europace/eux307, indexed in Pubmed: 29161368.

65. Liu Y, Zhan X, Xue Y, et al. Incidence and outcomes of cerebrovascular events complicating catheter ablation for atrial fibrillation. Europace. 2016; 18(9): 1357-1365, doi: 10.1093/europace/euv356, indexed in Pubmed: 26705560.

66. Medeiros De Vasconcelos JT, Filho SD, Atié J, et al. Atrial-oesophageal fistula following percutaneous radiofrequency catheter ablation of atrial fibrillation: the risk still persists. Europace. 2017; 19(2): 250-258, doi: 10.1093/europace/euw284, indexed in Pubmed: 28175286.

67. Dagres N, Anastasiou-Nana M. Prevention of atrial-esophageal fistula after catheter ablation of atrial fibrillation. Curr Opin Cardiol. 2011; 26(1): 1-5, doi: 10.1097/HCO.0b013e328341387d, indexed in Pubmed: 21099683.

68. Halbfass P, Müller P, Nentwich K, et al. Incidence of asymptomatic oesophageal lesions after atrial fibrillation ablation using an oesophageal temperature probe with insulated thermocouples: a comparative controlled study. Europace. 2017; 19(3): 385-391, doi: 10.1093/europace/euw070, indexed in Pubmed: 27540039.

69. Leo M, Pedersen MF, Rajappan K, et al. Premature termination of radiofrequency delivery during pulmonary vein isolation due to oesophageal temperature alerts: impact on acute and chronic pulmonary vein reconnection. Europace. 2017; 19(6): 954-960, doi: 10.1093/europace/euw102, indexed in Pubmed: 27247012.

70. Buchta P, Myrda K, Skrzypek M, et al. The influence of ablation power reduction associated with oesophagus location on pulmonary vein isolation results in patients with paroxysmal atrial fibrillation: six-month follow-up. Kardiol Pol. 2017; 75(11): 1171-1176, doi: 10.5603/KP.a2017.0137, indexed in Pubmed: 28715071.

71. Tran VN, Kusa S, Smietana J, et al. The relationship between oesophageal heating during left atrial posterior wall ablation and the durability of pulmonary vein isolation. Europace. 2017; 19(10): 1664-1669, doi: 10.1093/europace/euw232, indexed in Pubmed: 28204456.

72. Knecht S, Sticherling C, Reichlin T, et al. Reliability of luminal oesophageal temperature monitoring during radiofrequency ablation of atrial fibrillation: insights from probe visualization and oesophageal reconstruction using magnetic resonance imaging. Europace. 2017; 19(7): 1123-1131, doi: 10.1093/europace/euw129, indexed in Pubmed: 27358070.

73. Mugnai G, de Asmundis C, Velagic V, et al. Phrenic nerve injury during ablation with the second-generation cryoballoon: analysis of the temperature drop behaviour in a large cohort of patients. Europace. 2016; 18(5): 702-709, doi: 10.1093/europace/euv346, indexed in Pubmed: 26564954.

74. Saitoh Y, Ströker E, Irfan G, et al. Fluoroscopic position of the second-generation cryoballoon during ablation in the right superior pulmonary vein as a predictor of phrenic nerve injury. Europace. 2016; 18(8): 1179-1186, doi: 10.1093/europace/euv362, indexed in Pubmed: 26614521.

75. Martins RP, Hamon D, Césari O, et al. Safety and efficacy of a second-generation cryoballoon in the ablation of paroxysmal atrial fibrillation. Heart Rhythm. 2014; 11(3): 386-393, doi: 10.1016/j. hrthm.2014.01.002, indexed in Pubmed: 24389575.

76. Bahnson T. Preventing phrenic nerve injury during second generation cryoballoon ablation. JACC: Clinical Electrophysiol. 2016; 2(4): 515-517, doi: 10.1016/j.jacep.2016.03.011.

77. CABANA: Ablation Disappoints for AF vs Drugs, Questions Remain. https://www.medscape.com/viewarticle/896508 (Accessed November 1, 2018).

78. Dagres N, Varounis C, Gaspar T, et al. Catheter ablation for atrial fibrillation in patients with left ventricular systolic dysfunction. A systematic review and meta-analysis. J Card Fail. 2011; 17(11): 964-970, doi: 10.1016/j.cardfail.2011.07.009, indexed in Pubmed: 22041335.

79. Anselmino M, Matta M, Castagno D, et al. Catheter ablation of atrial fibrillation in chronic heart failure: state-of-the-art and future perspectives. Europace. 2016; 18(5): 638-647, doi: 10.1093/europace/euv368, indexed in Pubmed: 26857188.

80. Nedios S, Sommer P, Dagres N, et al. Long-term follow-up after atrial fibrillation ablation in patients with impaired left ventricular systolic function: the importance of rhythm and rate control. Heart Rhythm. 2014; 11(3): 344-351, doi: 10.1016/j. hrthm.2013.12.031, indexed in Pubmed: 24374320.

81. Marrouche NF, Kheirkhahan M, Brachmann J, et al. Catheter Ablation for Atrial Fibrillation with Heart Failure. N Engl J Med. 2018; 378(5): 417-427, doi: 10.1056/NEJMoa1707855, indexed in Pubmed: 29385358.

82. Ullah W, Ling LH, Prabhu S, et al. Catheter ablation of atrial fibrillation in patients with heart failure: impact of maintaining sinus rhythm on heart failure status and long-term rates of stroke and death. Europace. 2016; 18(5): 679-686, doi: 10.1093/europace/euv440, indexed in Pubmed: 26843584.

Cite this article as: Hindricks G, Sepehri Shamloo A, Lenarczyk R, et al. Catheter ablation of atrial fibrillation: current status, techniques, outcomes, and challenges. Kardiol Pol. 2018; 76(12): 1680-1686, doi: 10.5603/KP.a2018.0216. 